\title{
LA NUEVA NOVELA, PARADIGMA DEL POLIMORFISMO TEXTUAL
}

\author{
THE NEW NOVEL, PARADIGM OF TEXTUAL POLYMORPHISM
}

\section{ZENAIDA M. SUÁREZ M.*}

\section{RESUMEN}

A través de la técnica reescritural, basada en la acumulación barroquizante de fragmentos textuales previamente des(cons)truidos, parcialmente descontextualizados y, en ocasiones, reducidos a la anonimia, Martínez construye un texto que aglutina los contenidos necesarios para su propia lectura. Este texto denominado, nada azarosamente, La nueva novela, es capaz de provocar una inabarcable cantidad de lecturas, mayor o menormente complejas, en función del aparataje teórico, crítico, histórico y artístico que maneje el lector, convertido, a la manera cortazariana, en un agente activo necesario en la construcción del relato final de este texto polimórfico, para cuyo análisis ha sido creada la teoría que aquí se presenta.

Palabras clave: Juan Luis Martínez, La nueva novela, literatura chilena, reescritura, hipertexto, intertextualidad, hipermetatexto transdisciplinario, polimorfismo textual.

\section{ABSTRACT}

Through the rewriting technique, based on the accumulation of textual fragments in baroque previously des(cons)tructed, partly decontextualised and sometimes reduced to anonymity, Martinez constructs a text that brings together the necessary content for its own reading. This text called, nothing haphazardly, The New Novel, is capable of eliciting an unmanageable number of readings, more or less complex, depending

* El presente texto se enmarca dentro del proyecto CONICYT-FONDECYT Postdoctoral No 3160038: Heterogeneidades discursivas en la literatura chilena. Escisión y alumbramiento en los grupos "Trilce", "Tribu No" y "Café Cinema".

** Doctora en Literatura y Teoría de la Literatura. Académica en Universidad de los Andes. Santiago, Chile. Correo electrónico: zsuarez@uandes.cl 
on the theoretical, critical, historical and artistic devices that the reader handles, who becomes in the Cortazarean way, in an active agent needed in the construction of the final account of this polymorphic text, for whose analysis the theory here presented has been crated.

Keywords: Juan Luis Martínez, The New Novel, Chilean literature, rewrite, hypertext, intertextuality, transdisciplinary hyper-meta-text, textual polymorphism.

Recibido: 16.06.16. Aceptado: 28.02.17.

\section{INTRODUCCIÓN}

La certidumbre de que todo está escrito nos anula o nos afantasma.

Jorge Luis Borges, La biblioteca de Babel

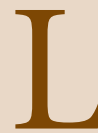

A IDEA BORGEANA del laberinto y la infinitud es parte inherente de una teoría que aborda la des(re)(cons)trucción del texto literario como un axioma epistémico e impulsa un sistema de pensamiento en torno a este, no solo como espacio de encuentros, sino de colisiones y oposiciones muchas veces no resueltas. El concepto de reescritura, que emana de esta consideración pluralista de la literatura y el arte, complejiza y aumenta las posibilidades de interacción del texto literario con respecto a sus referentes. Esta relación de hermanamiento e intercomunicabilidad de una obra con otra(s) anterior(es), si bien no siempre es claramente explicitada desde el hipertexto resultante, suele promover lecturas suspicaces que se intensifican una vez localizado el punto más claramente intertextual. Otras veces, sin embargo, las relaciones son múltiples y en la aglomeración de referencias, en la superposición de parecidos textuales, el lector pierde las pistas y acaba leyendo el conjunto como un original sin pasado.

Entendida así la reescritura ${ }^{1}$, como conglomerado heterogéneo, una de las obras más interesantes de la literatura chilena es La nueva novela (1977) de Juan Luis Martínez; objeto-arte que resulta de una aglutinación reescritural de múltiples textos, bien sean literarios, filosóficos, científicos o políticos, bien pertenezcan a la plástica, la pintura o la fotografía. Martí-

\footnotetext{
${ }^{1}$ Las teorías que trabajan y definen los textos que, de una forma $\mathrm{u}$ otra, surgen de la combinatoria textual son múltiples. Podríamos hablar de sistemas complejos de citación, apropiación, copia, plagio o collage; sin embargo, por razones de rigurosidad nominal, preferimos hablar de reescritura, eliminando así factores que constituyen tendencias de dudosa ética o de aglutinación simple que acompañan a las otras prácticas y elevando así a la calidad de novedoso el producto resultante.
} 
nez, que estaba convencido de que "sólo reescribimos palabras ya escritas por otros" (Roblero, 2003, p. 73), puso en marcha todo un mecanismo de reconstrucción de la obra de arte a través de la acumulación barroquizante de elementos de índole textual, paratextual, objetual y pictórico con los que logró desajustar el logos imperante en el arte.

A tenor de esto y a propósito de la recurrida idea de que la obra de Martínez es inabarcable, inclasificable e inexplicable, parece evidente que el problema de la interpretación de La nueva novela estriba en las herramientas que hasta ahora hemos utilizado para su análisis, pues se hace evidente la necesidad de un nuevo aparato crítico que logre des(cons)truirla a partir de las herramientas que nos proporcione una teoría ad hoc para hacer una serie de micro-lecturas o sacar un número concreto de conclusiones parciales a partir de las cuales cada lector pueda construir su propia nouveau roman. Es innegable la ventaja que supone partir de los estudios previos sobre el corpus específico que compone la obra martiniana, ya que las múltiples interpretaciones que se le han hecho han propiciado y articulado un campo crítico vastísimo sobre el cual sentar ciertas bases, como las referentes a la autoría múltiple, a la superación de los géneros literarios tradicionales, a los juegos paradojales y contralógicos o a la problemática de la nominación que surge de la ruptura del horizonte de expectativas provocada por un título novelesco para una obra que, a todas luces, parece estar signada por lo poético; un texto polimórfico que sin duda interpela al lector y lo desafía a situarse, cual Alicia incrédula, al otro lado del espejo, desde donde "Todo es posible" (André Breton).

\section{UN NUEVO MODELO PARADIGMÁTICO}

La nueva novela, auto-publicación de Juan Luis Martínez (Valparaíso, 1942 - Villa Alemana, 1993), sale a la luz por vez primera en enero de 1977. Eran aquellos unos años duros para la cultura y, sobre todo, para la vida. Instaurada plenamente la dictadura pinochetista, el año 1977 está plagado de hitos que dan sentido a ciertas categorizaciones factuales que lo marcan como un verdadero punto de inflexión con respecto a los años anteriores². Sin embargo, hay que ser cauteloso a la hora de contextualizar La nueva no-

\footnotetext{
${ }^{2}$ Los hitos ocurridos este año transcurren en medio de dos terribles huelgas de hambre de familiares de detenidos-desaparecidos y el suicidio, en Cuba, de Beatriz Allende, hija de Salvador Allende. En el mes de enero comienza a tener vigencia el impuesto a los libros y se clausura Radio Balmaceda, perteneciente a la Democracia Cristiana. En marzo, Augusto Pinochet disuelve todos
} 
vela, pues la lectura politizada se impone sobre lecturas de índole estrictamente literaria o técnica, sobre todo en el tipo de lector que en los primeros años alcanzó a leerla y que pertenecía al círculo literario, crítico o teórico del Chile post-golpe. Y es que no podemos perder de vista que la obra comienza a escribirse en 1968 y, según lo que reza el colofón, se terminó en 1975. Pero sabemos, también, que una primera versión ya estaba acabada y a punto de ser publicada por la Editorial Universitaria de Valparaíso en el año 1971, antes del golpe de Estado y en pleno gobierno socialista. Sobre esto, afirma Zurita:

Este libro, que se llamó hasta prácticamente el último minuto Pequeña cosmogonía práctica-que es un título de Tardieu- estaba prácticamente terminado el año 1973, cuando estuvo a punto de ser publicado con el título Pequeña cosmogonía práctica por la Editorial Universitaria. Y justo viene el golpe, por lo tanto no sale el libro, que ya estaba aprobado. Y ahora me despierta una curiosidad absolutamente sin respuesta porque "el papel secante"; lo que no estaba, que agregó al final Juan Luis, cuando cambia el título hacia La nueva novela, es "la bandera chilena". Creo que, ¡ah! y los peces esos de Cetus -esos con los anzuelos- son las únicas páginas nuevas que tiene con respecto a la versión del 73 que aprueba la Universitaria, con Pedro Lastra y Martín Cerda $(\text { sic })^{3}$ (Movimiento Lúdico Films, 2007) ${ }^{4}$.

los partidos políticos, a excepción de los de extrema derecha, como el Partido Nacional de Chile. En abril, el Ministerio del Interior prohíbe la importación de libros de Gabriel García Márquez, Mario Vargas Llosa y Julio Cortázar, autores de marcadísima influencia en los escritores chilenos que van a conformar la nueva tendencia neovanguardista de la literatura. Finalmente, en diciembre, Pinochet informa de la realización de una Consulta Nacional mediante la cual pretende legitimar el apoyo de la ciudadanía a la gestión de su gobierno y rechazar por ley la intervención extranjera. El plebiscito, llevado a cabo el 4 de enero de 1978, dio como resultado el sí con un amplio margen sobre el no $(78,6 \%)$ y en un ambiente de absoluta represión ciudadana.

${ }^{3}$ Transcripción del video titulado "Raúl Zurita sobre Juan Luis Martínez" en que el poeta hace una intervención a raíz de la presentación del video "Señales de ruta" de Tevo Díaz (2a edición). Publicada en Youtube.com: https://www.youtube.com/watch? $v=1$ UFBlbEvLZY\#t=11 (visitado por primera vez en enero de 2011)

${ }^{4}$ En realidad, "Pequeña cosmogonía práctica" no es una obra sino una parte del capítulo denominado "Petits problèmes et travaux pratiques" ("Pequeños problemas y trabajos prácticos") incluidos en Un mot pour un autre de Jean Tardieu (1951). Este capítulo concreto, no obstante, había visto la luz en 1948 en la revista uruguaya Asir, traducido al español por W. Lockhart. Por la exacta coincidencia de las traducciones, suponemos que Martínez tomó estos textos de la publicación uruguaya; aunque el germen del que nace el gusto de Martínez por Tardieu, con total seguridad, es el capítulo 152 de Rayuela (1963) denominado "Abuso de conciencia", traducción de "Abus de confiance" del libro de Tardieu La première personne du singulier (1952). 
Estas palabras de Zurita vienen a arrojar luz respecto de la tendencia que ve y analiza La nueva novela como una obra artística en pugna directa con el aparato represor de la dictadura chilena. Visto así, entonces, $\mathrm{La}$ nueva novela no es legible exclusivamente desde el contexto social, político y cultural en el que se inserta Martínez como sujeto al momento de su publicación sino que, por el contrario, entender su funcionamiento requiere de la aceptación de esta como una autoconstrucción contextual en cuya conformación podemos encontrar un importante número de textos que, legibles desde la misma obra, la vinculan claramente a los grandes procesos bélicos europeos: la Guerra Franco-Prusiana (1870), la I Guerra Mundial (1914) y la II Guerra Mundial (1939); e incluso a los regímenes despóticos de América Latina, sobre todo en el segundo cuarto del siglo $\mathrm{XX}$, pero no a la dictadura chilena como extratexto único y explícito. Así, una contextualización funcional que realmente aporte datos fehacientes para el análisis de La nueva novela, debe estar hecha sobre la base de dos grupos de elementos extratextuales que en muchos sentidos van a funcionar como intertextos:

1. El contexto histórico inmediato donde se sitúa la obra en el momento en que se publica, en plena dictadura.

2. El autoconstructo contextual, que en el caso de La nueva novela es una especie de híbrido entre los momentos históricos más importantes que pueden haber influido en la obra, las manifestaciones artísticas vigentes declaradas en ella y otro tipo de vinculaciones que pueden entreverse a lo largo de sus páginas pero que no son fuentes declaradas y que podemos denominar "hipotexto latente".

Desde esta nueva contextualización plural de La nueva novela se abre un vasto campo analítico donde toma mayor importancia la necesidad de desarrollar una teoría literaria acorde con la obra para que pueda ser analizada a la luz de sus propios textos y no de un contexto ficticio y vagamente afín a ella. Esta teoría, a la que denominamos "Teoría del texto polimórfico" es expuesta a continuación sobre la base de postulados teóricos primiciales que también serán detallados. 


\title{
LA NUEVA NOVELA Y LA TEORÍA DEL TEXTO POLIMÓRFICO
}

\begin{abstract}
¿Nunca os ha sucedido, leyendo un libro que os habéis ido parando continuamente a lo largo de la lectura y no por desinterés, sino al contrario, a causa de una gran influencia de ideas, de excitaciones, de asociaciones? En una palabra, ¿no os ha pasado nunca eso de leer levantando la cabeza?
\end{abstract}

R. Barthes, El susurro del lenguaje

El presente texto no trata de esclarecer o listar qué relaciones concretas establece La nueva novela con otros textos, autores o movimientos; es sobradamente conocido el campo crítico que a lo largo de los últimos años se ha formado y especializado acerca de estos aspectos, entre los que destacan las relaciones con OuLiPo y el Nonsense, la obra de Mallarmé, el orientalismo, el concretismo brasileño o el surrealismo ${ }^{5}$. Tratamos aquí, sin embargo, de desarrollar una teoría que, aunque parte de la propuesta de la narratología genettiana, la supera aumentándola, corrigiéndola y adaptándola a la obra de Martínez. Desde esta teoría que aquí se presenta puede abarcarse su propuesta de construcción del texto desde el concepto de reescritura, definido en pos de esta obra.

La primera afirmación que podemos hacer con respecto a La nueva novela de Juan Luis Martínez, y de la cual parte nuestra teoría, es que casi de forma privativa La nueva novela está compuesta por fragmentos textuales que funcionan como hipotextos metatextuales ${ }^{6}$, lo que obliga a definir una nueva función, basada en la transtextualidad, que Genette no definió: la "hipermetatextualidad transdisciplinaria", debido a la especial condición

\footnotetext{
${ }^{5}$ Críticos como Iván Carrasco, Óscar Galindo, Patricia Monarca, Valeria de los Ríos, Juan Herrera, Walter Hoefler, Gwen Kispatrick, Enrique Lihn y Pedro Lastra, Soledad Fariña, Elvira Hernández, Scott Weintraub o Matías Ayala, entre otros, han abordado algún aspecto de la reescritura y sus múltiples facetas en La nueva novela de Martínez, estableciendo importantes relaciones de la obra con otros textos, movimientos, tendencias o autores.

${ }^{6}$ Para evitar controversias, cabe aclarar que las denominaciones utilizadas a priori proceden de la teoría genettiana. Con esto pretendemos desambiguar la problemática que se establece entre términos como hipertexto/intertexto o intertextualidad/transtextualidad, e independientemente de que a posteriori reordenemos las clasificaciones dadas, este será nuestro punto de partida terminológico. Por otro lado, no solo los términos problematizan la teoría intertextual sino que, de acuerdo con el propio Genette, "no se deben considerar los cinco tipos de transtextualidad como clases estancas, sin comunicación ni entrelazamientos recíprocos”, creencia que ha propiciado la definición de un nuevo tipo de relación transtextual derivada; el "hipermetatexto transdisciplinario" que aparece al final de este texto. Finalmente, salvo error, los conceptos de diégesis, extradiégesis e intradiégesis no aparecen en este estudio. La razón de esta intencional obviedad es, evidentemente, la absoluta falta de "narración" de esta obra que, pese a llamarse La nueva novela, se resiste a ser analizada como tal porque viola constantemente los estratos de creación para los que generalmente se concibe una nouvelle.
} 
en que se reiteran los signos en esta obra. Los hipotextos que se insertan dentro de La nueva novela se sitúan en ella sin ningún aparente signo de orden cronológico ni temático y van generando, en función de otros (hipo) textos con los que les corresponda interactuar, fragmentos discursivos desde los que pueden irse leyendo algunos de los principios que presenta. Esta especial condición, que se concibe a partir de la declarada voluntad de Martínez de "construir un trabajo poético donde mi participación sea mínima, como un instrumento nada más de esa fuerza autónoma que es el lenguaje" (Roblero, 2003, p. 75) eclosiona en un producto heteroforme donde la reescritura se convierte en tendencia privativa de la construcción literaria. El autor no existe sino como un artesano que ha ido uniendo las piezas de un puzzle que el lector deberá, paradójicamente, deshacer para poder visualizar. Este lector des(cons)tructor, por lo tanto, también será un re-escritor y generará un nuevo texto a partir de los fragmentos textuales que logre decodificar y recodificar en su lectura.

Así, la falta de sistematización en torno a ciertos aspectos de la reescritura evidencia la necesidad de una reformulación de los aspectos más importantes que conforman la epistemología basada en los supuestos teóricos de Kristeva, la teoría del infinito, la rezeptionsästhetik, el estructuralismo, la teoría de la influencia y el palimpsesto, para adaptarla a las especiales condiciones en que La nueva novela hace uso de las relaciones transtextuales y que pueda funcionar en su tarea de definir a la obra.

Siguiendo la clasificación hecha por Genette en Palimpsestes (1982) reescritura entraría a formar parte de esta clasificación como uno de los tipos de transtextualidad descritos por él: la hipertextualidad, puesto que no es otra cosa que escribir un texto, llamado B, a partir de otro texto, llamado A, que funcionaría como hipotexto. Pero, ¿qué ocurre cuando el hipotexto es múltiple y el hipertexto, plural y multiforme?, ¿cómo logra decodificar el lector una obra que circula en el ámbito de la autoría múltiple? y ¿en qué grado es aplicable la teoría genettiana a un texto como La nueva novela? Las respuestas son variadas y de una complejidad nada desdeñable, sobre todo cuando, revisadas todas las propuestas teóricas, vislumbramos un vacío en el ámbito de la reescritura múltiple ${ }^{8}$.

${ }^{7}$ Utilizamos, para la revisión y el análisis, la edición española de 1989, traducida por Celia Fernández Prieto.

${ }^{8}$ No obstante, la bibliografía acerca de este tema es muy amplia y, desde los primeros textos de Kristeva sobre la intertextualidad hasta la actualidad, donde podemos destacar a críticos como Marcus Boon, Antoine Compagnon, Patrick Greaney, Frank Leibovici o Alberto Laiseca, entre otros, el volumen de textos que tratan el tema es tan variado y, en ocasiones, contradictorio como inabarcable.

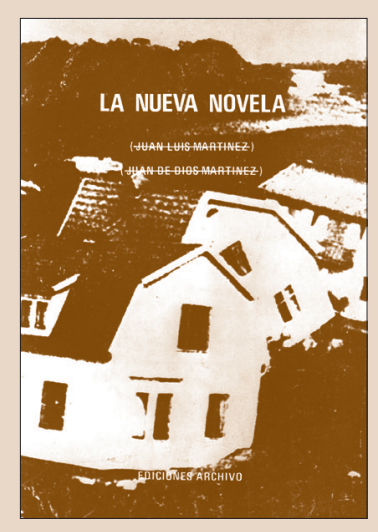


Uno de los aportes más lúcidos de Palimpsestes es su clasificación en seis tipos de las modalidades básicas de hipertextualidad, haciendo una distinción entre las dos formas en que un hipotexto puede derivar hacia el hipertexto resultante: derivación por transformación y derivación por imitación, que a su vez pueden ser de tipo lúdico (la parodia o el pastiche), satírico (el travestimiento o la caricatura) y serio (la transposición o la continuación, "forgerie"). No obstante, La nueva novela escapa a estas clasificaciones dadas por Genette debido a la fragmentariedad explícita con que están insertos los textos que la componen, lo que hace imposible la labor de lectura en el sentido más tradicional del término y, de igual modo, del trabajo de asimilación del estilo de escritura, que es, al fin y al cabo, una de las propuestas interpretativas de los semióticos.

Concluyentemente, los modos retratados por Genette sirven solo parcialmente en el análisis de La nueva novela, pues la práctica analítica que nos permitirá esclarecer los modos hipertextuales no estará basada en esta clasificación sino en el tipo de hipertexto que se genera de la aglutinación hipotextual ${ }^{9}$. En otras palabras, La nueva novela no permite una clasificación cerrada de sus prácticas hipertextuales, pero sí una tipificación medianamente organizada de los modos en que los hipotextos se relacionan con el hipertexto desde la mirada del lector que presentamos en nuestra teoría del texto polimórfico.

Por otro lado, hay dos aspectos de la reescritura sin los cuales no se entendería esta visión del fenómeno hipertextual: la funcionalidad y la ideología. Para Genette, la voluntariedad de la reescritura y sus dos posibles funcionalidades (social y estética) son rasgos dominantes a la hora de decantarse por un tipo u otro de hipertextualidad (1989, pp. 491-492), es decir, por la elección entre una parodia, un charge o un forgerie, por ejemplo.

En este sentido, a propósito de la funcionalidad de la obra de arte, la crítica martiniana ha fluctuado entre lo social y lo estético de forma constante, sin llegar a tasar explícitamente la diferencia esencial que las separa.

Desde los primeros escritos de Kristeva sobre la intertextualidad hasta la actualidad, donde podemos destacar a críticos como Marcus Boon, Antoine Compagnon, Patrick Greaney, Frank Leibovici o Alberto Laiseca (citados en bibliografía), el volumen de textos sobre este tema es tan variado y, en ocasiones, contradictorio como inespecífico para tratar la autoría múltiple reiterada, tal y como sucede en la obra de Martínez.

${ }^{9}$ La complejidad que supone este apartado estriba en provocar un cambio lo suficientemente importante pero sutil en las clasificaciones genettianas como para que puedan entenderse claramente las diferencias entre los distintos tipos de prácticas hipertextuales que conforman la nueva teoría del texto polimórfico. 
Sin embargo, la predominancia de las relaciones transtextuales esteticistas que hay en esta obra de 1977 hace posible la diversificación de opciones en este grupo, donde podemos diferenciar tres tipos de reescritura según su funcionalidad e intencionalidad:

1. Reescritura por asimilación: surge de la atracción de un autor por los textos de otro cuyos postulados comparte y desea "reescribir".

2. Reescritura por disimilación: un autor puede sentir la motivación de reescribir un texto para refutarlo directamente, parodiarlo o bien utilizarlo como ejemplo para postular una idea no complementaria a él.

3. Reescritura por adición: surge cuando no es ni la empatía ni el deseo de censura lo que motiva la reescritura, sino la unión de ambas; o sea, una admiración hacia el autor unida a la idea de que la obra admirada puede ser mejorada de algún modo o, en casos más extremos, adaptada a un contexto histórico, social o cultural diferente donde las ideas de la misma puedan seguir sirviendo de ejemplo.

Esta última clase de reescritura es la que una mayor gama de tipos reescriturales puede ofrecer, pues las técnicas que el autor-reescritor puede elegir para hacerla van desde el pastiche hasta la transposición.

El otro aspecto sin el cual la reescritura sería imposible es la ideología. Querer reafirmar, ocultar o tergiversar una ideología son las razones explícitas por las cuales existe la reescritura. Mismidad o alteridad mueven la voluntad artística como un fenómeno universal ideológicamente dependiente. En este sentido, se vuelve crucial prestar atención al hecho de que toda reescritura va a propiciar un desplazamiento histórico del texto previo (hipotexto) hacia un momento distinto en el que, sin embargo, adquiere total significación (como hipertexto); razón por la cual buena parte de los fragmentos textuales que componen La nueva novela han sido leídos a través del prisma político y cultural del Chile dictatorial ${ }^{10}$.

Estos aspectos hasta ahora analizados permiten definir la reescritura como el resultado de la aplicación voluntaria de los modos básicos de las prácticas hipertextuales en la conformación de un texto derivativo que obe-

${ }^{10}$ Uno de los casos más emblemático de estas lecturas descontextualizadas es el de las dedicatorias de Miguel Serrano que aparecen en los preliminares de La nueva novela y a cuya transposición nos referimos en el texto "La imagen intervenida. Fragmentariedades visuales en la obra de Juan Luis Martínez", publicado en el volumen Martínez total (2016) a cargo de Marcelo Rioseco y Braulio Fernández Biggs (eds.) en Editorial Universitaria. 
dece a una ideología concreta -explícitamente materializada o no- y que depende tanto del grado de compromiso del hipertexto con su hipotexto como de la funcionalidad que se le designe.

En el tránsito hacia la conformación de la teoría polimórfica que estamos definiendo es importante resaltar que los desplazamientos semánticos que provoca un hipertexto con respecto a su(s) hipotexto(s) se manifiestan por lo general en una serie de indicios que hacen reconocible la práctica reescritural. Estos desplazamientos suelen estar vinculados a una especial forma de recepción y se reconocen como transformaciones o imitaciones, bien sea de estilos, voces, características o, simplemente, cambios contextuales que promueven también un cambio en su recepción. Sin embargo, en La nueva novela, de un modo casi colérico, se traspasan todos los límites supuestos para la recepción de una obra como literaria. Esta manualidad producto del ensamblaje de fragmentos textuales, fotográficos, pictóricos y objetuales, aborda al lector violentamente y provoca en él un abrumador sentimiento de desconcierto y una sustancial crisis de todos los valores que este consideraba como intrínsecos a la creación literaria. La saturación que opera en La nueva novela, que desde su mismo título se ve intervenida por intertextos que actúan como fragmentos de un texto mayor ${ }^{11}$, estimula un cambio en la recepción proporcionado por las especiales condiciones en que se nos presenta.

Entre las más recurridas nominaciones que se han dado a La nueva novela cabe destacar la de collage. Efectivamente, si analizamos detalladamente la composición de la obra, el mecanismo de vincular fragmentos o trozos de otras obras, convierte este libro-objeto en un objeto-arte donde lo que suele ser la excepción se convierte en la norma: el ejercicio de la repetición extrema de la técnica reescritural. En este sentido es destacable la afirmación de Matías Ayala de que:

El collage y la serie son los procedimientos básicos con los que Martínez construye las páginas de sus volúmenes. El collage es el procedimiento para enlazar lo textual y lo visual en el espacio bidimensional del cuadro, el grabado y la página. Esta es la forma en que Martínez desnaturaliza las imágenes y muestra la arbitrariedad de su código visual (Ayala 2016, p. 311).

${ }^{11}$ No se debe perder de vista que "nueva novela" traducido al francés es nouveau roman, nombre que coincide con el nombre del movimiento literario acuñado por Robbe-Grillet y que se erige como uno de los máximos renovadores del género novelesco en el mundo, siendo muchas de sus técnicas claramente asimiladas en el trabajo de Martínez. 
A esta dimensión visual, además, debemos añadir la dimensión objetual que declara la obra de Martínez, donde el significante es muchas veces un significante palpable, $\mathrm{y}$ ambos aspectos, dimensión visual y objetual, conviven en el mismo nivel de praxis estética en que Juan Luis Martínez logró reconstruir todo un sistema de pensamiento basado en el aparente uso del automatismo surrealista como base de creación.

La forma en que se establecen las relaciones entre los textos tiene explicación desde el concepto de hipertexto que aquí se propone, incorporando a la definición genettiana ciertas características provenientes de la teoría informática que lo complementarán de manera clara y concisa para que adquiera las connotaciones que hasta ahora no habían podido adjudicársele.

Reconocido el hipotexto (un híbrido compuesto por un incierto número de textos que mediante la técnica reescritural son aglutinados y que oscila entre variados momentos de la historia, el arte, la literatura, la filosofía o las ciencias), establecidas las bases teóricas desde las que partirá el análisis (la superación de la teoría intertextual y la narratología de Genette) e identificada la problemática (la falta de sistematización de los postulados teóricos que logren dar respuesta al análisis de textos como el de Martínez), se hace necesario rellenar los espacios vacíos para lograr una teoría global de análisis de La nueva novela que tenga en cuenta dos aspectos primordiales: primero, que La nueva novela es un constructo heteroforme que apela a la existencia de un lector activo y competente que logre ir recomponiéndola en cualquiera de sus ilimitadas posibles lecturas a medida que va des(cons) truyéndola ${ }^{12}$; segundo, que el aparataje teórico del que debemos armarnos habrá de tender a la definición de esta obra como interdisciplinar y transtextual; es decir, poliforme. Estos aspectos van a promover un cambio paradigmático importante con respecto a las tendencias de analizar el arte como un hecho lineal y ficticiamente ordenado. Asimilar el caos y aceptar la inexistencia de un principio y un fin nos sitúa en un espacio semiótico que, de alguna manera, se asemeja al concepto de semiósfera lotmaniana (1996), pero que va más allá de las normalizadas estrategias discursivas utilizadas por los escritores y que tiende hacia la materialización de algo tan complejo y al mismo tiempo tan cotidiano como la transformación del pensamiento humano en discurso. Rellenar los espacios vacíos, como se anunciaba, va a requerir, según el análisis que nos compete, del desarrollo teórico de tres aspectos básicos de la teoría polimórfica: la transtextualidad, el hipertexto y el hipermetatexto transdisciplinario.

\footnotetext{
${ }^{12}$ De más está citar las propuestas acerca del re-nacimiento del lector de Roland Barthes, de José María Castellet o de Julio Cortázar.
} 


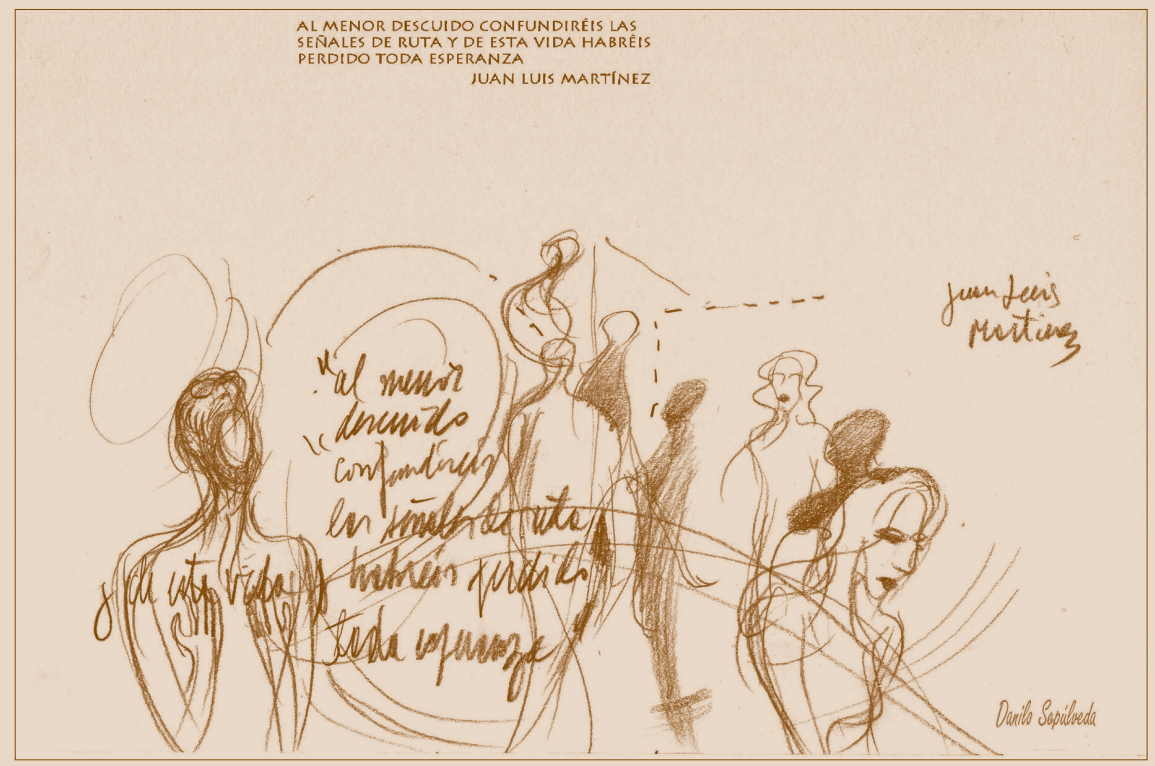

\section{El problema de la transtextualidad}

Esta investigación se basa en la idea de que lo único corroborable en la "escritura" de La nueva novela es la existencia de una intención reescritural. Sin embargo, en ese mismo sentido, también es importante no perder de vista que cada lectura crea La nueva novela. Por esta razón es importante situarse teóricamente desde la mirada del lector, que solo puede materializarse a través de propuestas como las de Iser del "lector implícito" o la del "lector modelo" de Umberto Eco, y será un lector hipertextual nacido de la teoría del texto como infinitud de relaciones, desde donde podremos distinguir tres tipos de texto:

a) Aquel que deriva de otros pero no depende semánticamente de ellos, o sea, no establecen una relación simbiótica con ellos para ser comprendidos en plenitud. Podrían contenerse aquí algunos de los objetos incluidos en $\mathrm{La}$ nueva novela, pues perdida su esencia fuera de la obra, dejan de necesitar su contexto real para ser leídos ${ }^{13}$.

${ }^{13}$ Este aspecto ha sido trabajado en el artículo citado en bibliografía "Objetualismo en Juan Luis Martínez. El significante palpable" (2013). 
b) El que deriva de otros intertextualmente y para el cual se impone la lectura palimpséstica; o sea, que es necesario leer B en relación con A para adquirir un sentido. Entonces, solo conociendo el hipotexto del que ha derivado el texto resultante podremos hacer una lectura exacta del mismo. Podríamos situar aquí, por ejemplo, "EL ANAGRAMA IDEAL DE DELIA EL TATUAJE IDEAL DE DELIA” (Martínez, 1985, p. 103), pues solo conociendo que ese dibujo es un detalle de la lámina de Dalí titulada "Portrait paranoïaque de Violette Nozziere" 14 podremos leer esta página como una crítica sarcástica (procedente de la parodización) a la doble moral de la sociedad burguesa, un guiño al método paranoico-crítico daliniano y una remisión al Diccionario abreviado del surrealismo de Breton y Éluard.

c) El derivado de otros textos cuya lectura palimpséstica es recomendable para reconocer o incrementar la recepción textual. Este es el caso de buena parte de las relaciones que la crítica sobre Martínez ha hecho, estableciendo relaciones de copresencia entre La nueva novela y otros autores, textos o movimientos como el simbolismo mallarmeano, el Nonsense, OuLiPo, el surrealismo o el concretismo. Ante la posibilidad de la existencia de muchos intextextos distintos lo más cabal es apelar a la competencia del lector, pues, sin ella, ninguna parodia o pastiche podría leerse como tal. Podemos aquí citar como ejemplo el caso de "Respuestas a problemas de Jean Tardieu" de La nueva novela con respecto a "Pequeños problemas y trabajos prácticos" de Un mot pour un autre de Jean Tardieu, que durante muchos años se leyó al margen de la obra del escritor francés y que, a medida que se lo ha ido vinculando con su real hipotexto, ha dado lugar a lecturas más complejas y explícitas ${ }^{15}$.

\footnotetext{
${ }^{14}$ Del “Retrato paranoico de Violette Nozziere”, así como del libro completo titulado en italiano Gruppo Surrealista. Violette Nozières, en el que una serie de autores y pintores del surrealismo (André Breton, Salvador Dalí, René Char, Yves Tanguy, Paul Éluard, Marx Ernst, Maurice Henry, Victor Braumer, E.L.T. Mesens, René Magritte, César Moro, Marcel Jean, Benjamin Peret, Hans Arp, Guy Rosey y Alberto Giacometti) hacen honor a la figura de esta mujer sometida a escarnio público y a la mirada de la doble moral de la burguesía francesa como un ejemplo de la tendencia social del arte surrealista, se hablará detenidamente en un texto en preparación que se titulará (tentativamente) "Surrealismo pictórico en La nueva novela" y que también contendrá un análisis de las propuestas de Magritte, Picasso y Matta contenidos en la obra.

${ }_{15}$ También la relación de transformación paródica travestida que se da entre "Respuestas a problemas de Jean Tardieu” y "Pequeños problemas y trabajos prácticos" será parte importante del análisis, que por razones de espacio debe ser fragmentado en varios textos para su publicación.
}

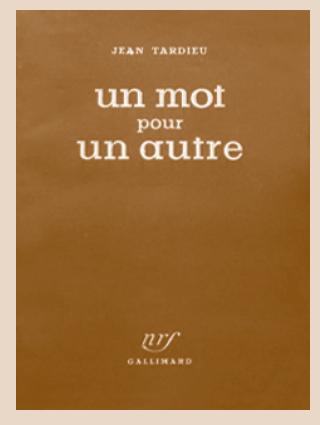


En resumen, las relaciones de copresencia de dos o más textos (Genette, 1989) pueden darse en diferentes regímenes simbióticos (dependencia o individualización) según el grado de inclusión que el hipotexto tenga en el hipertexto.

\section{El hipertexto}

Si bien en el campo de las humanidades la noción de "hipertexto" está vinculada al texto literario y a la emblemática figura de Gerard Genette, lo cierto es que adjudicar el nacimiento de este término a la teoría y crítica literaria es un error, pues es la informática la que lo pone en circulación ${ }^{16}$. "Hipertexto" es un término acuñado en 1965 por el tecnólogo, filósofo y sociólogo Ted Nelson (1937), aunque su origen se remonta hasta 1945, cuando Vannevar Bush (1890-1974) publicó "As we may think", donde hace una crítica al modo en que se gestiona la información como si fuera una estructura secuencial de documentos, influida por la secuencialidad del discurso hablado.

Veinticinco años más tarde Ted Nelson bautizó el fenómeno descrito por Bush como "hipertexto"17 en Literary Machines 93.1 (1992). Nelson define la cultura escrita como un conjunto complejo en el que cada elemento (texto) está conectado a los demás, bien sea explícita o implícitamente. Pero, al contrario de lo que parece haberse instalado como la nota común, consultar la base de datos, el hipertexto (La nueva novela, en nuestro caso), no es sinónimo de leer el texto, sino que es necesario enfocar la atención en cada "lexía" (Barthes, 2004) para establecer las concomitancias semánticas

\footnotetext{
${ }^{16}$ No significa esto que fuera del ámbito de la informática no existiesen indicios anteriores que apuntaran hacia la idea de un texto infinitamente interconectado (interna y externamente) con otros textos. Barthes, por ejemplo, en $S / Z$ (1970), hablaba de un texto formado por bloques de palabras (o imágenes) unidos de múltiples formas e infinito, donde ciertos enlaces electrónicos conectan unas partes con otras; un texto formado por "lexías" (fragmentos de otros textos) que, según Foucault, se asemeja a una red interconectada por nexos, ya que "las fronteras de un libro nunca están claramente definidas" (Foucault, 2002, p. 4). No cabe duda de que estas ideas de interconexión están íntimamente relacionadas también con la teoría rizomática de Félix Guattari y Gilles Deleuze, que consideraban el rizoma, no como estructura en forma de árbol (jerárquica) sino como elementos de múltiple funcionalidad dependiendo de factores externos a su composición (Deleuze y Guattari, 2004 [1970]).

${ }^{17}$ El texto en el que Nelson da nombre, por vez primera, al fenómeno hipertextual, se titula "A File Structure for the complex, the changing and the indeterminate" y es una conferencia leída en el congreso ACM 20th National Conference de 1965. Posteriormente desarrolla toda su teoría de forma más completa en su obra Literary Machines 93.1 (1992 [1980]).
} 
que van a unir cada texto con los demás y, finalmente, des(cons)truir el hipertexto, que será un concepto basado en dos premisas: la no-linealidad y la discontinuidad del discurso en el sentido en que un texto puede ser no-lineal y, sin embargo, mantener la continuidad textual; y cuyo caso más emblemático es Rayuela (1963) de Julio Cortázar ${ }^{18}$. En este tipo de construcciones, entonces, será el lector el que deba construir un relato según su bagaje cultural y/o su reconocimiento hipotextual. Podría parecer que esta libertad extrema que se da al lector resulta peligrosamente irresponsable para la conformación del hipertexto, ya que podrían ejercerse lecturas erráticas o absolutamente sacadas del núcleo textual dominante. Sin embargo, hasta la más extrema lectura que se haga del hipertexto estará circulando dentro de unos límites canónicos guiados por los nexos (lexías) hipotextuales, representados por asociaciones de tipo sináptico o lógico-deductivo.

La ausencia de orden fijo para estructurar el contenido discursivo (lo que Deleuze y Guattari llamaron “estructura rizomática”) es la especificidad del hipertexto. En su disposición fragmentaria se reconoce y confirma la soberanía del lector en el campo epistemológico de la literatura y problematiza las acciones textuales que pueden darse en la lectura hipertextual como distintos niveles de complejidad, entre los que podemos citar las relecturas en contextos diferentes, los juicios acerca de los dos términos de una alternativa o la parodización de un texto en un contexto determinado.

No obstante, en la lectura lineal se van generando pensamientos (relaciones, recuerdos, parecidos...) que dotan a esta de una dimensión distinta y que, en su conjunto como acto interpretativo, también puede denominarse "hipertexto". A tenor de esto, podemos aseverar que la escritura hipertextual en soporte informático viene, simplemente, a ofrecer un nuevo espacio de expansión en la conceptualización que siglos atrás ya venían ejerciendo autores como Stendhal o Dostoievsky, pues los conceptos de unicidad, finitud y fijación de que parece liberarse el hipertexto informático, no son más que la parte más externa de un proceso de creación mucho más complejo.

\footnotetext{
${ }^{18}$ Podemos recordar, a propósito de Rayuela y la conformación del hipertexto, el diálogo del capítulo 154 entre Morelli, Oliveira y Ettiene, cuando el viejo escritor desde la cama de hospital donde se encuentra accidentado, pide a sus culposos visitantes que lleven unos papeles (capítulos de esa obra inconclusa que está creando) y los pongan en un lugar concreto que él mismo les señala (entre los capítulos 51 y 53). Ante la posibilidad de equivocarse que plantea Oliveira, Morelli responde: "Mi libro se puede leer como a uno le dé la gana. Liber Fulguralis, hojas mánticas, y así va. Lo más que hago yo es ponerlo como a mí me gustaría releerlo. Y en el peor de los casos, si se equivocan, a lo mejor queda perfecto” (Cortázar, 1984, p. 737).
}

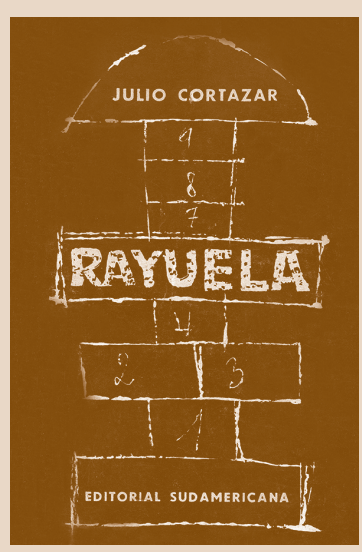




\section{El hipermetatexto transdisciplinario}

Desde el aparataje teórico de que nos hemos servido en los párrafos anteriores hemos tratado de describir la teoría polimórfica (o hipermetatextual transdisciplinaria) para limitar la enorme brecha existente entre los textos que presentaban algún tipo de hipertextualidad, pues había muchas obras que podían definirse desde este prisma que, sin embargo, poseían variados niveles de contenido extra-, inter- y metatextual. Así, podíamos llamar obra hipertextual a Cien años de soledad del mismo modo que a La nueva novela cuando en su forma, contenido y composición es más que evidente la distancia que las separa. La razón de la existencia de este espectro tan amplio y significativamente vacío estriba en la falta de categorización de la naturaleza del (los) hipotexto(s), pues si bien en Cien años de soledad (1967), por ejemplo, somos capaces de reconocer inmediatamente algunos pasajes de La Biblia como un modo de representar otra realidad a partir de la hiperrealidad ficcional, en La nueva novela, la reescritura es el fin y el medio por el cual se construye el discurso. Es decir, hagamos la lectura que hagamos, cuando des(cons)truimos cualquiera de los fragmentos textuales que conforman la obra nos encontramos con el esbozo de un discurso metatextual que vuelve sobre sí mismo para resignificarse como axioma. Así, si tomamos como ejemplo, entre los muchos que presenta La nueva novela, a las figuras de Adolf Hitler y Tanya Sávicheva, podemos descubrir una construcción metatextual que se lee a sí misma en su contexto real y opera como denuncia del horror provocado por el Holocausto nazi pero que, insertándola en el ámbito explícito del discurso, funciona como clave hipertextual, de un lado, a partir del reconocimiento de dos hipotextos (la historia de Tanya Sávicheva y el nazismo), y como clave metatextual, de otro, pues en la lectura de los fragmentos que contienen estas figuras contrapuestas nos vemos obligados a remitirnos a extratextos sobre ellos que nos ayuden a concretar su posible significación. A partir de esta fusión extremadamente barroca con el resto de los textos que dialogan al interior de La nueva novela, se genera un constructo semántico de proporciones infinitamente mayores a las imaginadas en cada lectura parcial, lo que constituye y da lugar a un hipertexto extremo y metatextual, oscilante entre infinitud de campos del conocimiento, el arte y las ciencias: el hipermetatexto transdisciplinario.

$\mathrm{Y}$ es que hablar de La nueva novela es hablar de un texto multiforme y heterogéneo, que altamente interconectado con otros textos, inagotable y siempre abierto a múltiples re-interpretaciones, demuestra la vigencia de la teoría borgeana del infinito y lo absoluto, retratada en múltiples ocasiones 
por él y que, como ya esbozamos, podría resumirse en la máxima de que "La certidumbre de que todo está escrito nos anula o nos afantasma" para darle autonomía absoluta al texto y su lector cómplice.

\section{REFERENCIAS}

Ayala Munita, M. (2016). "El collage y la serie en la obra de Juan Luis Martínez". En Fernández Biggs, B. y M. Rioseco (eds.) Martínez total (pp. 309-319). Santiago, Chile: Editorial Universitaria.

Barthes, R. (2004 [1970]). S/Z. Buenos Aires, Argentina: Siglo XXI editores.

Bush, V. (1945). "As we may think". En The Atlantic Monthly (01 de julio de 1945): s/p. En: http://iibi.unam.mx/ voutssasmt/documentos/Vannevar_ Bush_Como-\%20podriamos\%20_Pensar_JV.pdf (10/12/2014).

Cortázar, J. (1984 [1963]). Rayuela. Edición de Andrés Amorós. Madrid, España: Editorial Cátedra.

Deleuze, G. y F. Guattari (2004 [1970]). Mil mesetas. Capitalismo y esquizofrenia. Valencia, España: Pre-Textos.

Foucault, M. (2002 [1969]). La arqueología del saber. Buenos Aires, Argentina: Siglo XXI editores.

Genette, G. (1989 [1982]). Palimpsestos. Literatura en segundo grado. Trad. Celia Fernández. Madrid, España: Ed. Taurus.

Gruppo Surrealista (2001 [1933]). Violette Nozières. Prefazione di Andrea Bruni. Italia: Maldoror Press.

Lotman, Y.M. (1996). La semiósfera I. Semiótica de la cultura y el texto. Selección y traducción de Desiderio Navarro. Madrid, España: Ed. Cátedra.

Martínez, J. L. (1985 [1977]). La nueva novela. Santiago, Chile: Ediciones Archivo. (2003). Los poemas del otro. Santiago, Chile: Universidad Diego Portales.

Movimiento Lúdico Films (2007). "Raúl Zurita sobre Juan Luis Martínez". En Presentación de Señales de Ruta de Tevo Díaz. On-Line: https://www.youtube.com/watch?v=lUFBlbEvLZY\#t=11 (12/01/2011)

Nelson, T. (1992 [1980]). Literary Machines 93.1. On-line: http://utx.net/ccritics/lm0.html (02/11/2014).

Roblero, M. E. (2003). "Ya no tengo miedo a la muerte”. En Martínez, J. L., Poemas del Otro. Santiago: Ediciones Universidad Diego Portales.

Suárez M., Z. (2013). “Objetualismo en Juan Luis Martínez: el significante palpable”. Estudios Filológicos 51, 83-98.

. (2016). "La imagen intervenida. Fragmentariedades visuales en la obra de Martínez". En Fernández Biggs, Braulio y Marcelo Rioseco (eds.) Martínez total (pp. 321-337). Santiago, Chile: Editorial Universitaria.

Tardieu, J. (2003). CEuvres. París, Francia: Gallimard. 